\title{
Cytoplasmic RNA
}

National Cancer Institute

\section{Source}

National Cancer Institute. Cytoplasmic RNA. NCI Thesaurus. Code C84512.

RNA present in the cytoplasm. It is involved in the protein export process from the cells. 